\title{
3-D Temporary Facility Visualization Using BIM (Building Information Modeling) Technology
}

\author{
Hyunjoo Kim ${ }^{1}$, Hongseob $\mathrm{Ahn}^{2}$, and Wooyoung $\mathrm{Kim}^{3}$
}

\begin{abstract}
The key role in safety management is to identify any possible hazard before it occurs by identifying any possible risk factors which are critical to risk assessment. It is well known that falsework (temporary facilities) in construction projects is fundamentally important. This planning/assessment process is considered to be tedious and requires a lot of attention due to the following reasons: firstly, the installation and dismantling of those facilities are one of the high risk activities in the job sites. Secondly, temporary facilities are generally not clearly delineated on the building drawings. Therefore, it is our strong belief that safety tools have to be simple and convenient enough for the jobsite people to manage them easily and be flexible for any occasions to be occurred at various degrees. In order to develop a safety identification system of temporary facilities, this research utilizes the BIM technology in retrieving important information by importing data from BIM models and use it in the safety planning stage.
\end{abstract}

Keywords: Safety management; Building Information Modeling (BIM); Data Exchange; 3D modeling, Safety Management, ifcXML

\section{INTRODUCTION}

In spite of various efforts of safety professionals and strong governmental reinforcement, its high frequency and severity of injuries and illness have not decreased well enough in the construction industry. The recent development in BIM (Building Information Modeling) technology encourages us to utilize it in the field of accident prevention as well as in design and project management.

The key role in safety management is to identify any possible hazard before it occurs by developing prevention measures which are critical to risk assessment. This planning/assessment process is considered to be tedious and requires a lot of attention due to the following reasons: firstly, falsework (temporary structures) in construction projects is fundamentally important. However, the installation and dismantling of those facilities are one of the high risk activities in the job sites. Secondly, temporary facilities are generally not clearly delineated on the building drawings. It is our strong belief that safety tools have to be simple and convenient enough for the jobsite people to manage them easily and be flexible for any occasions to be occurred at various degrees.

When it comes to the physical representation of a computerized model, current CAD systems are mostly used for actual models of buildings, depicting the static results of design and construction. While these models provide a topological description of buildings in the way different objects (or entities) are connected together and store specific architectural features and attributes, it is recognized that $\mathrm{CAD}$ programs typically represent buildings mostly as geometric models. Information flow from design to construction is critical and, when efficiently controlled, it allows for design-build and other integrated project delivery methods to be favored. The impact of BIM processes has been more evident in cutting-edge buildings and innovative processes. Utilizing the BIM technology, this paper developed a new methodology of modeling an installation and dismantling of falseworks in construction projects. Using the methodology developed in this research, it is expected that the construction manager could create falsework models (temporary structures) imbedded with necessary guidelines and regulations containing the safety related requirements of a building in the planning/ assessment process. This research established a procedure of Building Information Modeling (BIM) modeling technique in identifying possible hazard(s) by visually simulating falsework objects, and their locations of a building. The prototype described in the paper is mainly for designing a scaffolds layout of a building, but could be developed further in planning on various temporary facilities.

\section{PREVIOUS RESEARCH}

Year after year construction is one of the most dangerous industries, with approximately 1,050 construction workers dying on the job each year (Reese \& Edison, 2006). Although construction employment equals just over $5 \%$ of the workforce, construction injuries account for in excess of $17 \%$ of all occupational deaths. One out of every seven construction workers is injured each year and one out of every fourteen will suffer a disabling injury.

\footnotetext{
${ }^{1}$ Assistant Professor, California State University, 800. N. Stage College Blvd, Fullerton, CA, USA, hykim@ fullerton.edu (*Corresponding Author)

${ }^{2}$ Professor, Architectural Engineering, Kunsan University, 573-701 Daehangno 1170, Gunsan, Jeonbuk, Korea, hsahn@kunsan.ac.kr

${ }^{3}$ Senior Researcher, Construction \& Economy Research Institute of Korea, 71-2, Gunsul hoikwan, Nonhyun-Dong, Kangnam-Gu, Seoul, Korea, beladomo@cerik.re.kr
} 
Jaselskis et al. [1] developed a strategy for improving construction safety performance and Hinze et al. [2] measured the number of safety violations and fatalities which revealed interesting trends. Interestingly, Carter et al [3] focused on the safety hazard identification on construction projects and described that unidentified hazards [resent the most unmanageable risks. The research utilized an IT (Information Technology) tool in construction project safety management with a computerized module. De la Garza et al. [4] analyzed safety indicators in construction projects and Hinze et al [5] did research in identifying factors that significantly influence the safety performance of specialty contractors. Jannadi et al [8] worked on the assessment of risk for major construction activities. And Kartam [9] emphasized the importance of effective planning and control techniques to prevent construction accidents.

It is found that a number of researchers have illustrated how designers have implemented collaborative work via 3D modeling with contractors to enhance constructability ([5], [7], [11],). In that sense, we believe that BIM is one of the most recent technologies that has gained acceptance in the AEC industry.

This study intends to develop a safety simulation system based on the BIM technology which will enable the jobsite people to plan ahead on safety management and eventually achieve more productivity. One of the possible benefits from the BIM based safety assessment system can be efficient hazard identification at the planning process which will focus on the movements of workers incorporated with other resources such as different kinds of equipment, materials and tools. In order to develop the safety assessment system, this research utilizes the BIM technology and collects important information by importing data from BIM models and use it in the planning stage.

\section{RESEARCH METHODOLOGY}

Based on the literature review made in the previous section, it is recognized of a need to develop a temporary facility simulation system utilizing the BIM technology for a construction manager to automate the processes of installing and dismantling the temporary facilities in a construction project. Figure 1 describes the entire process, starting with a (a) BIM model created in a commercial program and ending with (d) 3-D safety simulation with scaffolds. Major BIM design software such as ArchiCAD enables us to export data in an ifcXML which is a main data exchange format in this research. ifcXML was used throughout the paper since it is a non-proprietary, open standard defined by the buildingSMART and supported by various government officials and the AEC industry in the US. The research process proposed in this paper begins with extracting building geometry and material information of a BIM model and combining the requirements of temporary facilities to build a safety management system for the installation and dismantling of the falseworks. To better understand the information in
ifcXML files, an exemplary view of how the ifcXML file is displayed in Figure 2, which shows how the first section of important information is stored. There are three very important pieces of information in this section: directional element id definitions, starting coordinates of the various elements, and the direction each element is created in from its starting location. The directions are defined per unit of length in a three dimensional plane. For example, the id can be defined as $(1,0,0)$ which moves from its starting location 1 unit in the $x$ plane, 0 units in the $y$ plane, and 0 units in the $z$ plane.

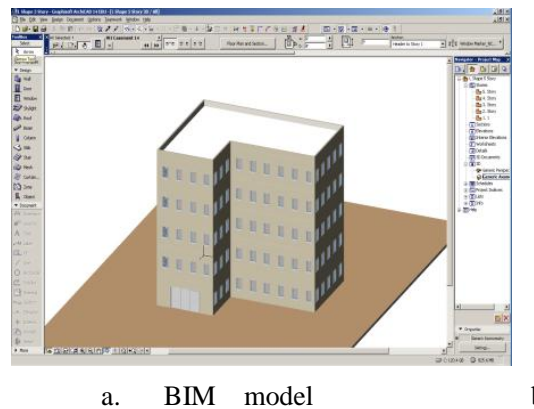

Safety regulations OSHA 1926.250 General Requirements 1926.451 Subpart L, General requirements, Scaffolds 1926.500 Subpart M, Fall Protection

a. BIM model

b. Safety Regulations and guidelines

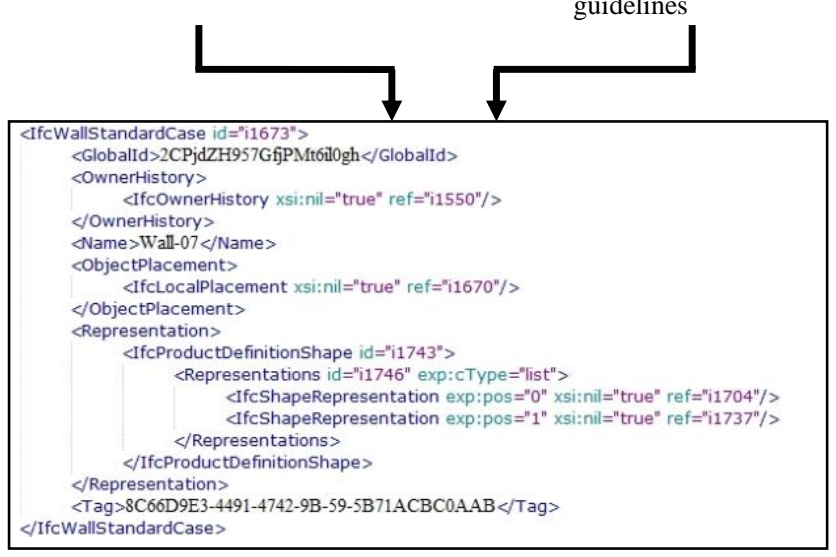

c. BIM model in ifcXML

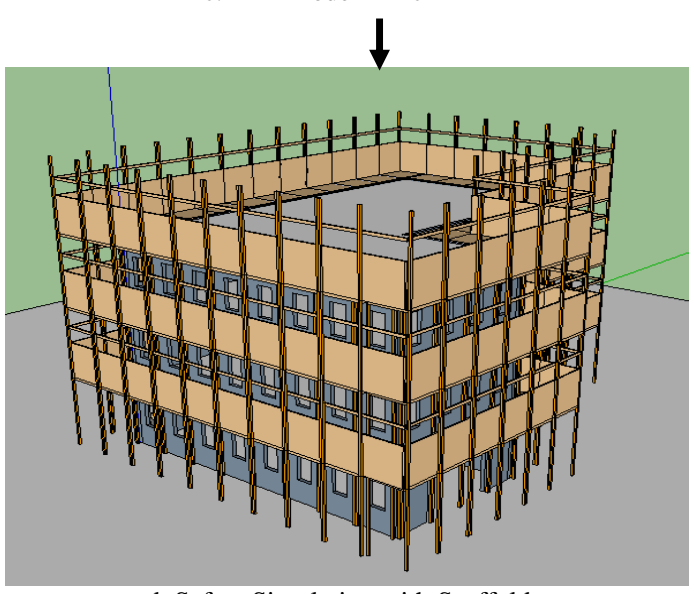

d. Safety Simulation with Scaffolds

FIGURE 1

Process of BIM DATA AND 3D MODEL 
In this paper, the scaffolds were built to demonstrate the hazard identification process as part of automatic extraction of requirements and identification of all the temporary facilities from a BIM data by saving the BIM model in ifcXML. In figure 1 , an example of a 5 story office building is shown in CAD representation and stored in ifc file (shown in the figure background). Next, the types of scaffolds and their locations are taken from the ifc file after it is saved in ifcXML. Finally the safety management system developed in this research will identify temporary facilities and their locations. Details of modeling process are described in the next section.

ifcXML files even for very simple BIM produce very long and complex files. The model used in this paper consisted of only a small number of walls, doors, roofs, and slabs, yet the ifcXML file was almost 8,000 lines of code.
Figure 3 below, is a very small exert from the ifcXML file created by the BIM used in this paper. This exert is describing the length in inches of the northern wall, or the second wall, based on order of construction in the BIM, as it is described in the file. To extract the information regarding the length of the wall we have to write the following ruby code:

target[IfcShapeRepresentation] ['i1803']['Items']['i180 8'][IfcPolyline] ['i1799''][Points] ['i1802']

['IfcCartesianPoint'][1]['Coordinates']['i1798']['IfcLen gthMeasure'][0]

The information is referenced by indexes essentially. The first thing that is called out is to find the first level of the index, IfcShapeRepresntation.

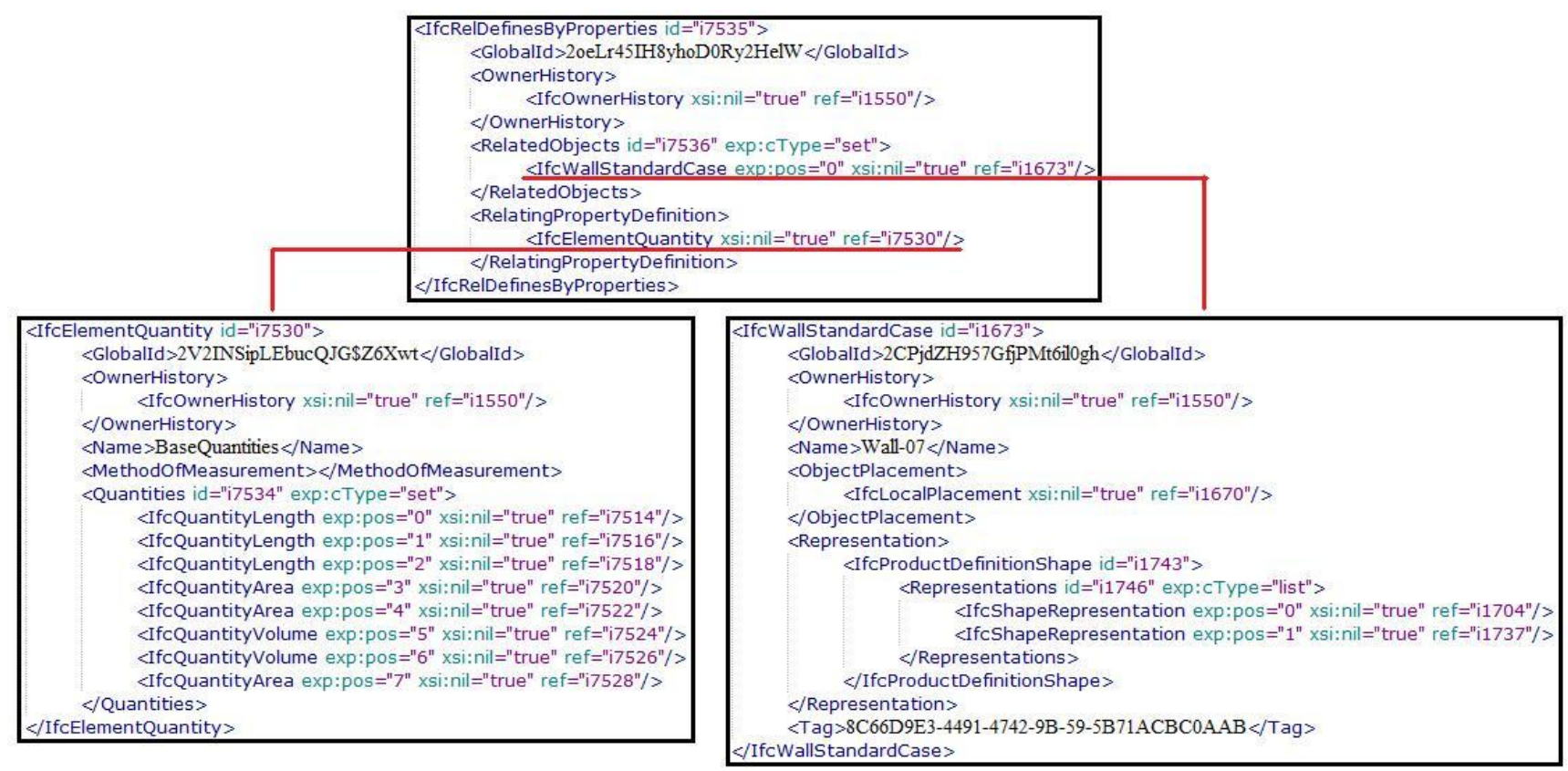

FIGURE 2

ENHANCED VIEW OF THE IFCXML FILE

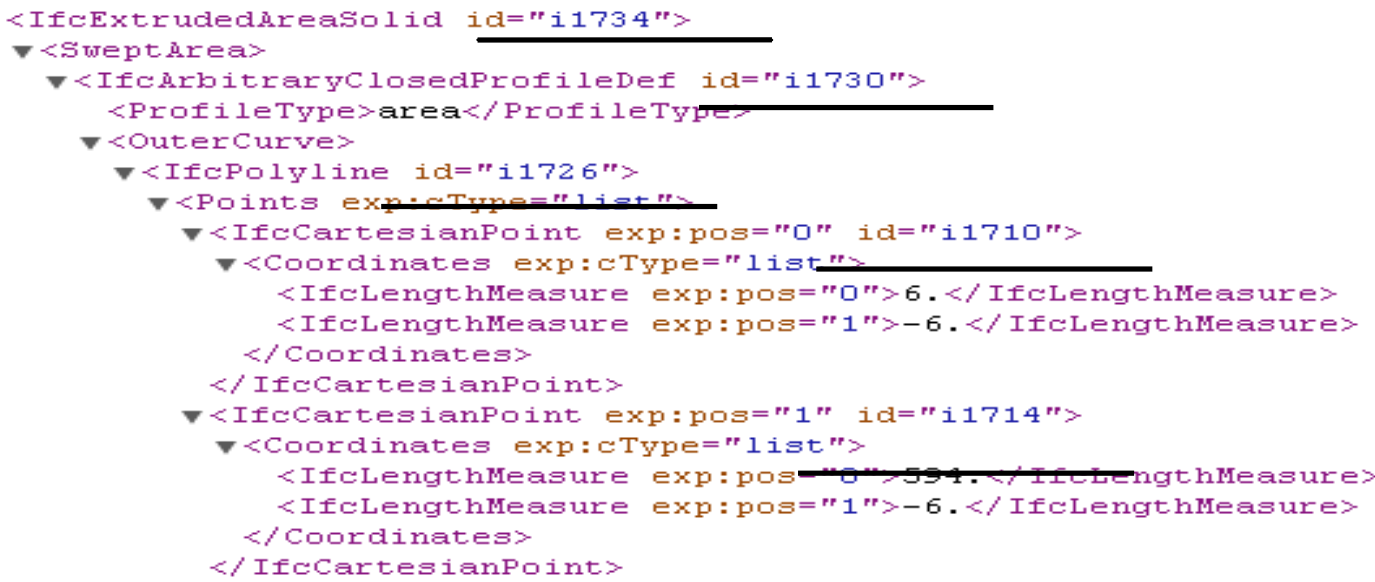

FIGURE 3

INDEXED ELEMENT INFORMATION IN IFCXML FILE 


\section{CASE STUDY}

This section describes a case study to illustrate the process of establishing a hazard identification model corresponding with the building design represented in a BIM and using it to automatically identify types and locations of different temporary facilities in the construction phase. The process consists of six steps shown in:

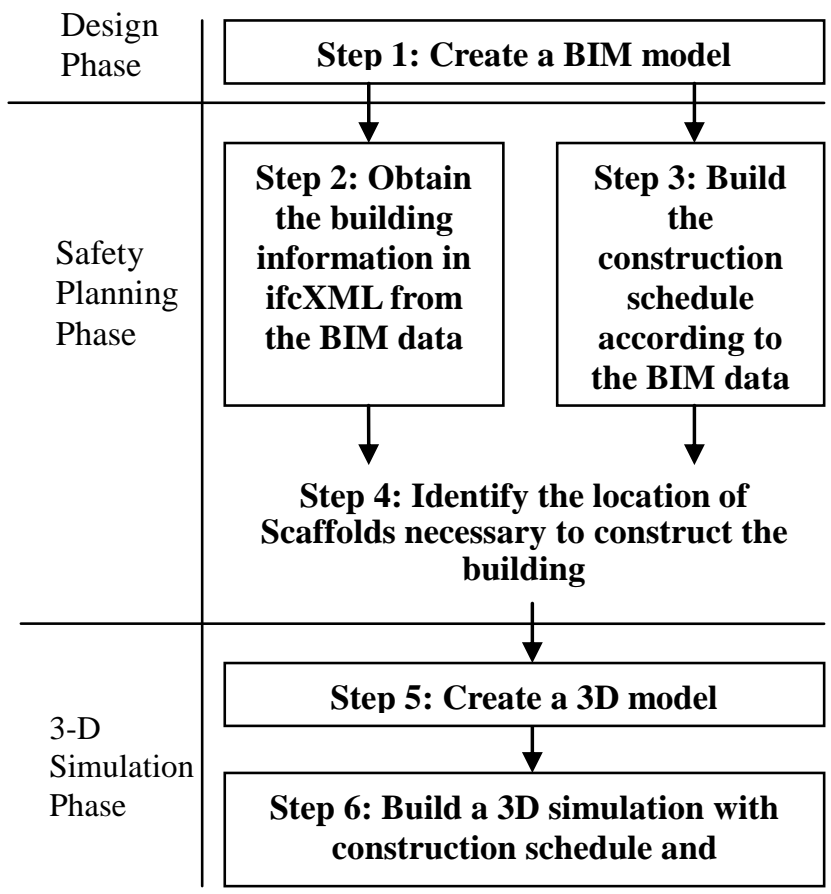

FIGURE 4

RISK ASSESSMENT PROCESS USING BIM

\section{Step 1: Create a BIM model}

In our risk assessment process, the BIM technology was used to extract the geometry of a building to enable modeling with data from the instance data model to build a 3D model. ArchiCAD software was used to build a BIM model, which was saved in a non-proprietary standard model, ifcXML. Figure 5 shows a BIM model of a five story office building, built in ArchiCAD.

Step 2: Obtaining the building geometry from the ifcXML data.

ifcXML is an XML format defined by ISO 10303-28 (STEP-XML), having file extension "ifcXML". This format is suitable for interoperability with XML tools and exchanging partial building models. In general, the size of an XML data file from an architectural design may easily excess several MB. It is not economic to deal with such a large amount of data in extracting building geometry from a BIM model. In this research, a Web-based XML file reader was developed for the XML transformation purpose. The building information for any building design objects such as walls, floors, slabs has been easily extracted and transformed into a 3D visual model.

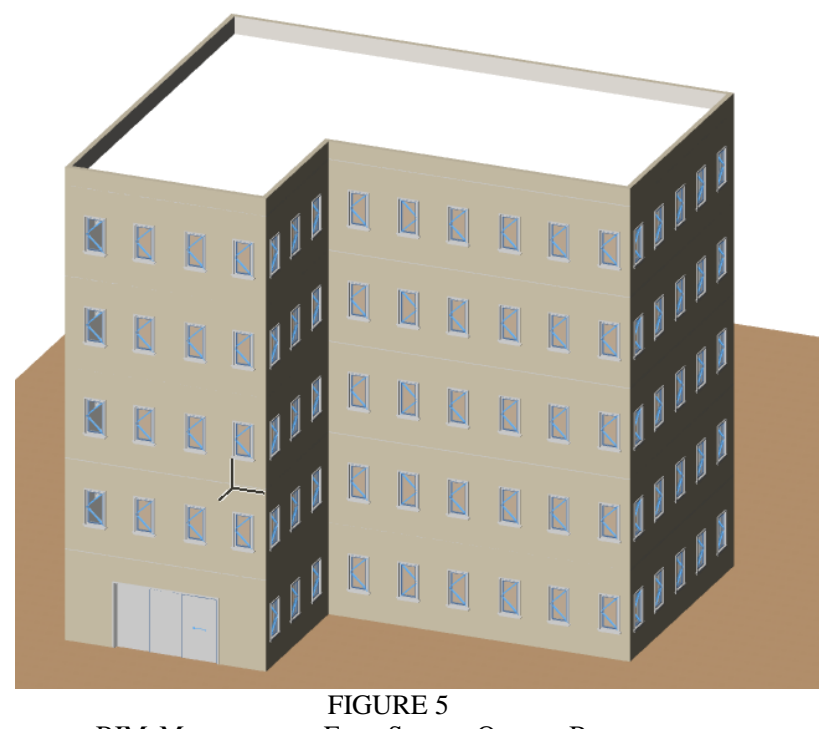

BIM Model of A Five STORY OFFice BuILding

\section{Step 3: Build the construction schedule according to the BIM data}

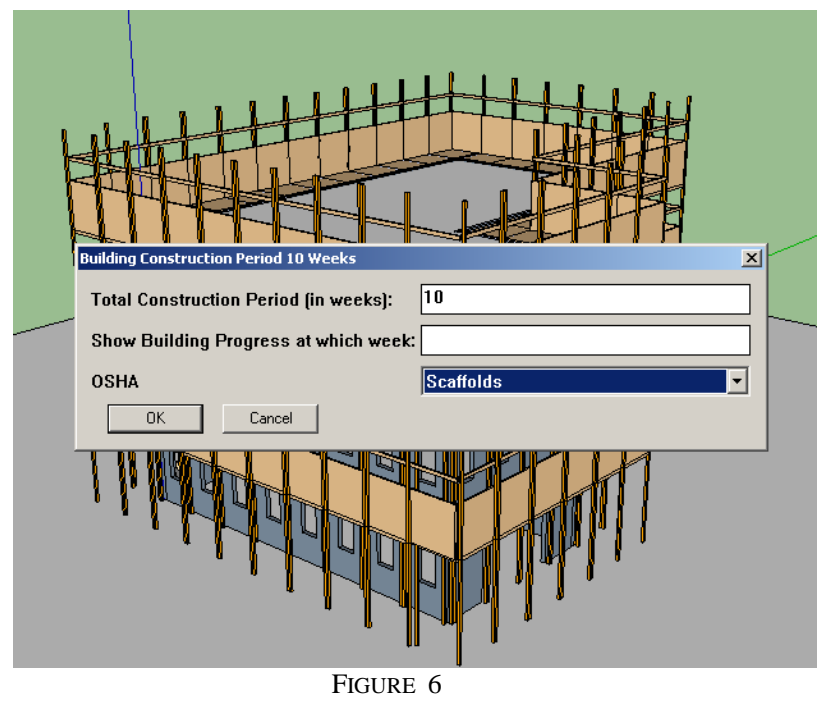

BIM Model with Schedule Information

In this step, all the building components are retrieved and stored in the safety management system. Next step is to calculate the amounts of each building component such as walls, floors, slabs, finishes, and openings. In this case study, the building area is 15,000 SQFT. According to the standard estimation, each floor is to be completed in two weeks, totaling 10 weeks to complete the five story office building. Figure 6 shows the entire progress of the construction schedule could be segmented into ten different weeks from the prediction of the amounts of each component in the office building. Figure 6 also shows a 3D model which has completed the second floor of the 
building along with scaffolds built around the perimeter of the building.

\section{Step 4: Identify the location of the scaffolds necessary to construct the building}

The use of scaffolds as tools for working at varied levels on construction sites, is a fixture in the construction industry. Unfortunately, there have been many accidents involving scaffolding. There could be many different reasons for the accidents. But one of the important reasons is many scaffolds have been improperly installed because of the lack of knowledge, or the lack of misunderstanding on the exact locations of the scaffolds. They must be designed, installed, loaded and dismantled properly in full accordance with OSHA regulations.

Besides the scaffolds, each worker is to be provided with additional protection from falling hand tools, debris, and other small objects through the installation of toe boards, screens, or guardrail systems. In this research, one of the scaffolds, carpenters' bracket scaffolds was applied and an example of the scaffolds and its guardrails are shown in Figure 7.

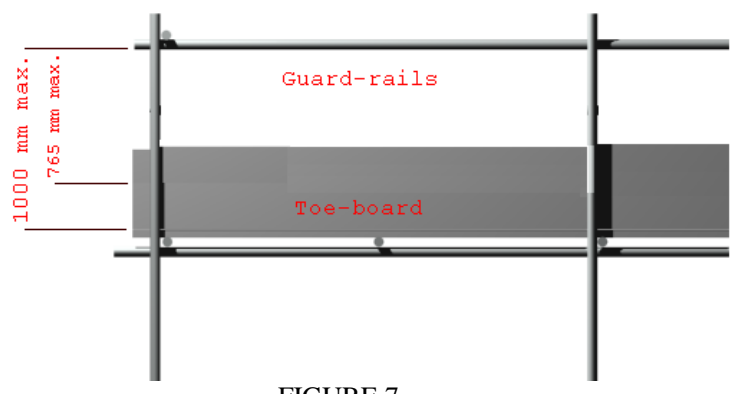

FIGURE 7

SPECIFICATIONS OF SCAFFOLDS

\section{Step 5: Create a 3D model}

In this step, a 3D model of the BIM model is regenerated in a computer program, called Google SketchUp. The reason that we used the SketchUp is a commonly used software program with software extensions known as "Rubies" written in Ruby programming language to augment the capabilities of SktechUP 3D modeling.

In the programming, the time sequence of the building construction is combined and added into scaffolds specifications and visualized in a 3D model in Google SketchUp.

\section{Step 6: Build a 3D simulation with construction schedule and scaffolds}

As shown in Figure 8, 3D simulation is built along with construction schedule and temporary facility (scaffolds) in Google SketchUp. For the purpose of simplicity, each floor of 3,000 SQ FT is to be constructed in two weeks. Therefore, scaffolds are to be placed on each floor according to its construction schedule.

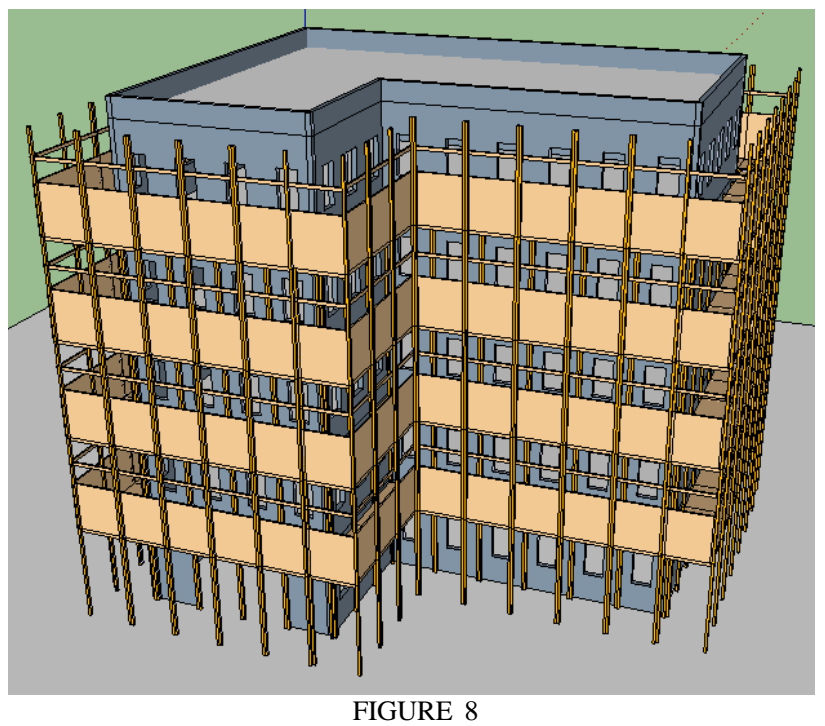

3D SIMULATION IN GOOGLE SKETCHUP

\section{CONCLUSIONS}

In spite of various efforts of safety professionals and strong governmental reinforcement, its high frequency and severity of injuries and illness have not decreased well enough in the construction industry.

This research applied BIM technology in safety planning process by allowing the construction manager to automatically visualize temporary safety facilities as part of construction process planning.

This research demonstrated a procedure of Building Information Modeling (BIM) modeling technique in identifying possible hazard(s) by visually simulating falsework objects, and their locations of a building. The safety management system proposed in the paper showed in the case study that BIM technology could be used to optimize the design process to create safer construction environments and illustrate the process of establishing a hazard identification model corresponding with the building design represented in a BIM and using it to automatically identify types and locations of different temporary facilities in the construction phase.

Utilizing the BIM technology, this paper proposed a new methodology so that a construction manager could create falsework models imbedded with safety regulations and guidelines containing the safety related requirements of a building in the planning/assessment process. This research demonstrated a procedure of Building Information Modeling (BIM) modeling technique in assessing possible hazards by visually representing falsework objects, and their locations in a building. The prototype described in the paper is mainly for designing a scaffolds layout of a building, but could be developed further in planning on various temporary facilities.

This research utilized the BIM technology and collects important information by importing data from BIM models and use it in the planning stage. 


\section{REFERENCES}

[1] E. Jaselskis, S. Anderson, J. Russel, "Strategies for Achieving Excellence in Construction Safety Performance", Journal of Construction Engineering and Management, vol. 122, no. 1, pp. 6170, 1996.

[2] J. Hinze, D. Russel, "Analysis of Fatalities Recorded by OSHA", Journal of Construction Engineering and Management, vol. 121, no. 2, pp. 209-214, 1995.

[3] G. Carter, S. Smith, "Safety Hazard Identification on Construction Projects", Journal of Construction Engineering and Management, vol. 132 , no. 2 , pp. 197-205, 2006.

[4] J. Garza, D. Hancher, L. Decker, "Analysis of Safety Indicators in Construction", Journal of Construction Engineering and Management, vol. 124, no. 4, pp. 312-314, 1998.

[5] B. Hadikusumo, S. Rowlinson, "Integration of virtually real construction model and design-for-safety-process database", Automation in Construction, vol. 11, no. 5, pp. 501-509, 2002.

[6] J. Hinze, J. Gambatese, "Factors That Influence Safety Performance of Specialty Contractors", Journal of Construction Management and Engineering, vol. 129, no. 2, pp. 159-164, 2003.
[7] T. Huang, C. Kong, H. Guo, A. Baldwin, H. Li, "A virtual prototyping system for simulating the construction process", Automation in Construction, vol. 16, no. 5, pp. 576-585, 2007.

[8] O. Jannadi, S. Almishari, "Risk Assessment in Construction", Journal of Construction Management and Engineering, vol. 129, no. 5, pp. 492-500, 2003.

[9] N. Kartam, "Integrating Safety and Health Performance into Construction CPM", Journal of Construction Management and Engineering, vol. 123, no. 2, pp. 121-126, 1997.

[10] C.D. Reese, J.V. Eidson, "Handbook of OSHA Construction Safety and Health", CRC/Taylor \& Francis, pp. 1-5, 2006.

[11] S. Slaughter, "The link between design and process: Dynamic process simulation models of construction activities", in 4D CAD and Visualization in Construction: developments and applications, Eds. R.R.A. Issa, I. Flood, W.J. O’Brien, Taylor \& Francis, pp. 145164, 2003. 